\title{
ANALISE METALOGRÁFICA DE FIXADORES EM VEÍCULOS DE ORIGEM FRANCESA ${ }^{1}$
}

\author{
André Ricardo Moraes Rodrigues Serra ${ }^{2}$ \\ Ana Paula Piris Rodrigues ${ }^{2}$ \\ Marcos Chogi lano
}

\begin{abstract}
Resumo
Numa economia globalizada, a oferta de produtos das mais diversas origens, está cada vez mais presente no cotidiano dos consumidores. Um exemplo típico é o mercado automobilístico, com a chegada e instalação de novas montadoras das mais diversas origens, ofertando produtos com preço convidativo, maior número de itens de série e prazos de garantia mais estendidos, elevou a competitividade entre elas. Neste contexto, as montadoras francesas que já se estabeleceram em mercados acirrados como na América do Norte e Ásia, investiram instalando plantas produtivas em território nacional e surgem como alternativas no mercado. Em 2010, foram produzidos 321.927 veículos por montadoras de origem francesa instaladas no Brasil e cerca de 3.000 veículos franceses foram importados e emplacados. Neste trabalho, foram analisados elementos fixadores de automóveis de montadoras de origem francesa e como resultados foram obtidos informações interessantes a respeito das estruturas e conformação destes elementos.
\end{abstract}

Palavras-chave: Fixadores; Metalografia.

\section{METALLOGRAPHIC ANALYSIS OF VEHICLE FASTNERS OF FRENCH ORIGIN}

\begin{abstract}
In a globalized economy, the supply of products from many different origins is increasingly present in the daily lives of consumers. A typical example is the automotive market with which the arrival and installation of new automakers from many different origins, offering products with affordable prices, a higher number of standard items and longer extended warranty periods, raised competitiveness between them. In this context, French automakers that have already established themselves in fierce markets such as in North America and Asia, have made investments installing productive plants in the country and have emerged as alternatives in the market. In 2010, a French automaker installed in Brazil produced 321,927 vehicles and about 3,000 French vehicles were imported and were given license plates. In this paper the fastening elements of cars from automakers of French origin were analyzed and as a result interesting information was obtained about the structure and conformation of these elements.
\end{abstract}

Key words: Fasteners; Metallography.

1 Contribuição técnica ao $68^{\circ}$ Congresso Anual da ABM - Internacional, 30 de julho a 2 de agosto de 2013, Belo Horizonte, MG, Brasil.

2 Graduando em Tecnologia Mecânica, Faculdade de Tecnologia de Sorocaba "José Crespo Gonzales", Sorocaba, SP, Brasil.

3 Doutorado em Engenharia Mecânica, Professor Associado II, Faculdade de Tecnologia de Sorocaba "José Crespo Gonzales", Sorocaba, SP, Brasil. 


\section{INTRODUÇÃO}

Os primeiros registros de utilização dos parafusos e porcas rosqueados datam do século XV. Segundo Niemann:(1) "as definições de parafuso mais usuais são determinadas como um eixo cilíndrico ou cônico envolvido por uma hélice". O perfil da hélice pode ser triangular, trapezoidal, dente de serra, redondo ou quadrado, sendo o perfil triangular o mais empregado em fixação, precisão e vedação, o perfil trapezoidal tem sua utilização em fixação, movimentação, quando os esforços são importantes, o perfil dente de serra tem sua aplicação em movimentação, a redonda presta-se a movimentação com choques.

Niemann ${ }^{(1)}$ descreve: "os materiais aplicados na confecção dos parafusos e porcas são bastante variados, sendo o mais empregado o aço por apresentar características mecânicas interessantes e capacidade de atenderem as solicitações das máquinas". Aço inoxidável, titânio, bronze e plástico também são utilizados na fabricação de parafusos, tendo suas aplicações em situações onde a resistência a corrosão, solicitações elevadas e isolação elétrica são requeridas.

Outras características são determinantes para o conjunto parafuso e porca como tipo de cabeça, a classe de resistência que esta relacionada com as tensões aplicáveis a cada elemento, ângulo da hélice, passo da hélice, passo da rosca, passo da hélice, número de hélices, direção da hélice (direita ou esquerda), etc.

Os objetivos deste trabalho são: determinar as características dos fixadores utilizados em rodas dos automóveis, verificar as durezas destes materiais e correlaciona-las.

\section{MATERIAL E MÉTODOS}

Neste trabalho foram analisados parafusos de fixação das rodas de automóveis de origem montadoras de origem francesa:

- Amostra 1 - montadora A;

- Amostra 2 - montadora B; e

- Amostra 3 - montadora C.

A técnica empregada na observação das microestruturas dos aços estudados foi a microscopia ótica, onde um feixe de luz visível incide paralelamente ao eixo do microscópio sobre a amostra e é refletida através de um sistema de espelhos chegando até o observador. O modelo utilizado neste estudo foi o microscópio "Cut-off" que utilizou um disco abrasivo de alumina com refrigeração metalográfico binocular invertido.

Segundo Rohde ${ }^{(2)}$ e Samuels:(3) "as amostras foram seccionadas no sentido longitudinal (Figura 1) através da serra policorte forçada", O disco abrasivo utilizado foi o 3045 , indicado para aços até $0,45 \%$ C. 


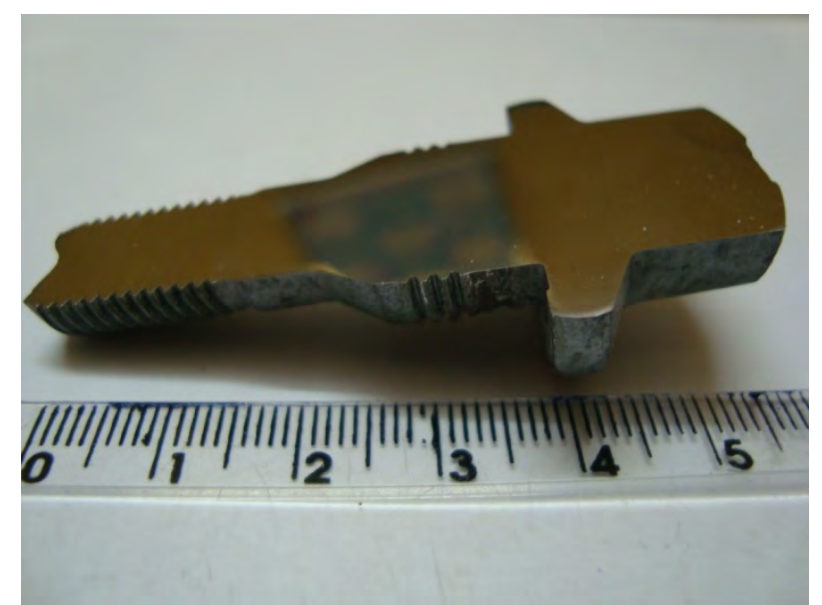

Figura 1. Fixador cortado no sentido longitudinal.

A operação de embutimento foi realizada com o equipamento que acondicionou a amostra no baquelite através de temperatura e pressão da ordem de $125 \mathrm{kgf} / \mathrm{mm}^{2}$ a $150 \mathrm{kgf} / \mathrm{mm}^{2}$, exercida pela prensa do equipamento por um tempo de aproximadamente 10 minutos.

A etapa de lixamento foi realizada até o grau de acabamento requerido para cada situação. A técnica consistiu em se lixar as amostras sucessivamente com lixas de granulometria cada vez menores, mudando-se a direção de lixamento em $90^{\circ} \mathrm{em}$ cada lixa subsequente até que superfície fica sem risco aparentes. As granulometrias das lixas empregadas foram de 220, 400, 600. Após esta etapa, o polimento foi realizado com pasta diamantada a fim de proporcionar um bom acabamento a superfície, em seguida foi realizada a limpeza com água e álcool etílico. O ataque químico foi realizado com nital a $3 \%$.

A analise química foi realizada em um espectrômetro de emissão ótica, utilizando tecnologia de detectores CCD, com sistema ótico de faixa espectral de $175 \mathrm{~nm}$ a 590 nm e câmera de excitação purgada com argônio para analise química de metais em amostras sólidas.

\section{RESULTADOS}

A analise química dos fixadores é mostrada na Tabela 1 e na Figura 2 pode-se visualizar uma comparação entre as amostras. Na Tabela 2 são indicadas as médias das durezas medidas nas amostras.

Tabela 1. Composição química dos fixadores analisados

\begin{tabular}{|l|c|c|c|c|c|c|c|c|c|c|c|}
\hline & $\mathrm{C}(\%)$ & $\mathrm{Si}(\%)$ & $\mathrm{Mn}(\%)$ & $\mathrm{P}(\%)$ & $\mathrm{S}(\%)$ & $\mathrm{Cr}(\%)$ & $\mathrm{Mo}(\%)$ & $\mathrm{Ni}(\%)$ & $\mathrm{Al}(\%)$ & $\mathrm{Co}(\%)$ & $\mathrm{Cu}(\%)$ \\
\hline amostra 1 & 0,279 & 1,39 & 1,26 & 0,02 & 0,01 & 0,16 & 0,008 & 0,024 & 0,02 & 0,005 & 0,026 \\
\hline amostra 2 & 0,401 & 0,079 & 0,86 & 0,01 & 0,01 & 0,2 & 0,011 & 0,02 & 0,04 & 0,005 & 0,013 \\
\hline amostra 3 & 0,359 & 0,092 & 0,86 & 0,01 & 0,01 & 0,18 & 0,011 & 0,027 & 0,034 & 0,006 & 0,048 \\
\hline
\end{tabular}


$68^{\text {th }} \mathrm{abm}$ international annual congress

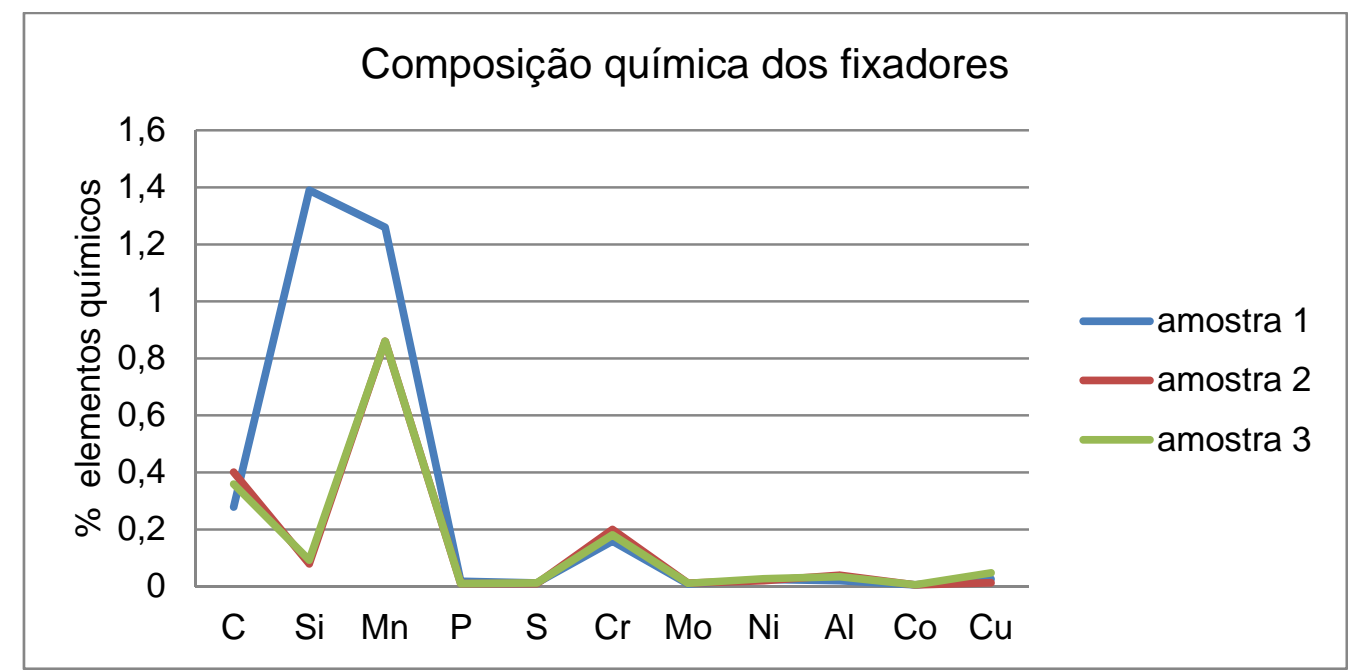

Figura 2. Resultado da analise química das amostras.

Tabela 2. Média das durezas das amostras

\begin{tabular}{|c|c|}
\hline Amostra 1 & $99 \mathrm{HRB}$ \\
\hline Amostra 2 & 29HRC \\
\hline Amostra 3 & $23 \mathrm{HRC}$ \\
\hline
\end{tabular}

A micrografia das estruturas das amostras foi gerada por meio de cortes no sentido longitudinal dos fixadores (Figura 3).
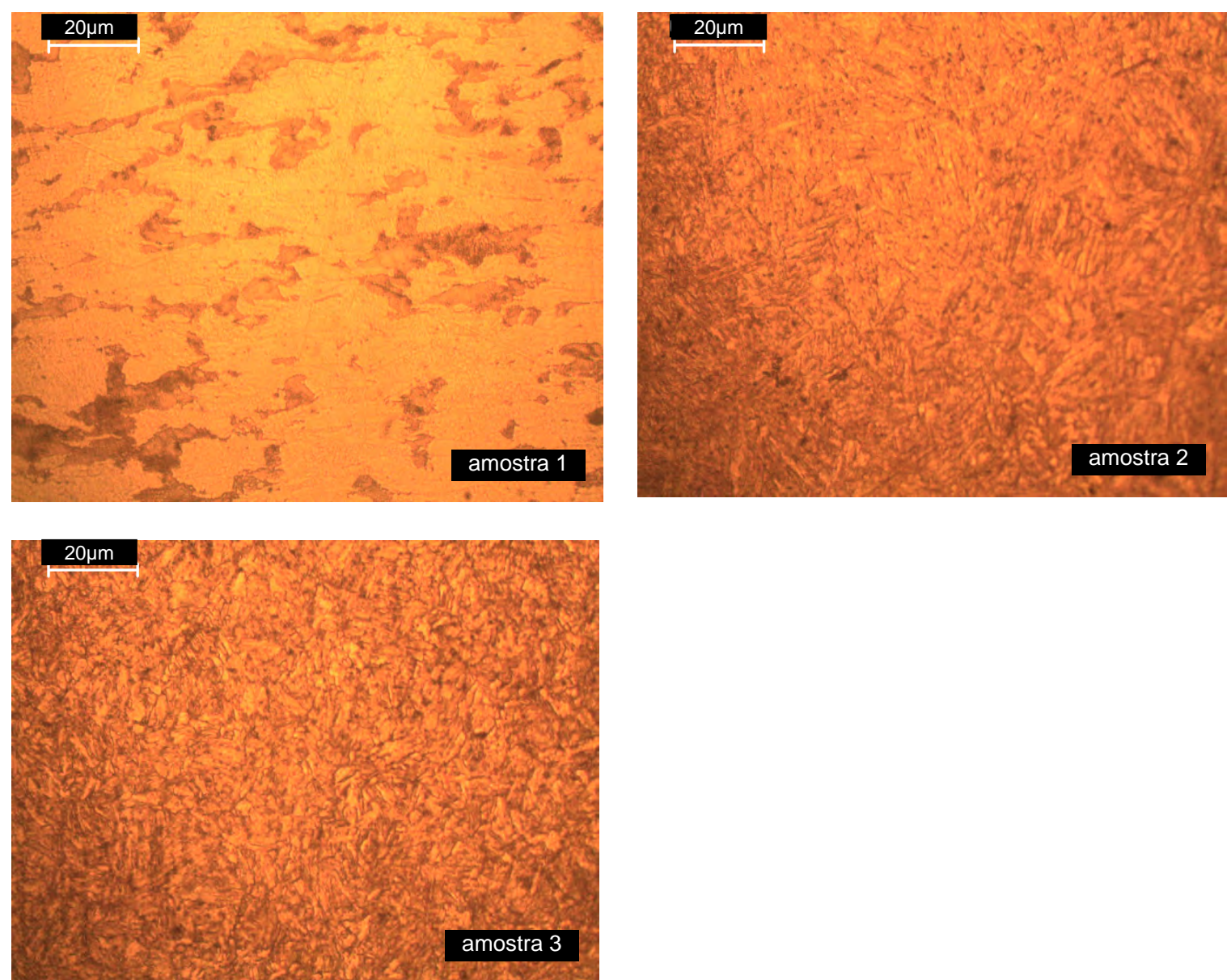

Figura 3. Imagens micrográficas das estruturas dos fixadores. 
Observando a amostra 2 constatou-se que a superfície do fixador apresenta uma camada descabonetada de aproximadamente $100 \mu \mathrm{m}$ (Figura 4).

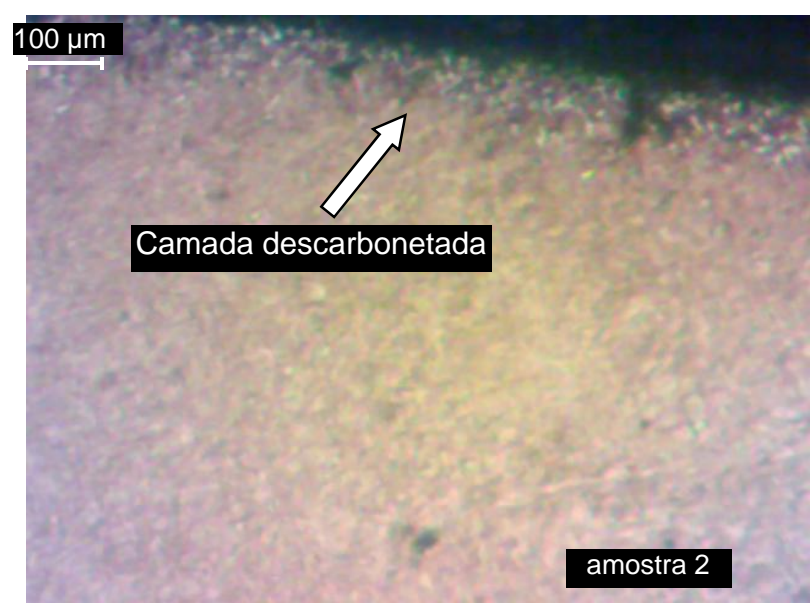

Figura 4. Amostra 2 com camada descarbonetada.

\section{DISCUSSÕES}

Baseado na analise química, a amostra 1 apresenta uma porcentagem de 1,39 sendo aproximadamente 15 vezes mais do que a médias das demais amostras. Segundo Souza:(4) "o silício nestas proporções associado a teores não elevados de manganês, fósforo e enxofre podem aumentar a dureza e a resistência mecânica, em contra partida a tenacidade diminui".

Além do silício a amostra 1 apresenta um valor diferenciado de manganês $(1,26 \%)$. Souza ${ }^{(4)}$ descreve que nestas porcentagem o elemento: "proporcionará melhores propriedades ao impacto", também interessantes nestes elementos que estão sujeitos a estas solicitações.

De acordo com Copaert ${ }^{(5)}$ e Padilha e Ambrozio(6) "baseado nas imagens da micrografia do material constata-se que existem dois conjuntos de estruturas". $\mathrm{Na}$ amostra 1 observa-se predominância de ferrita e nas amostras 2 e 3 verifica-se a presença de martensita.

Analisando-se os valores médios das durezas medidas nas amostras constata-se que na amostra 1 o valor médio da dureza se apresenta inferior as demais amostras, fato que se explica pela formação diferenciada das microestruturas que formam os materiais das amostras.

$\mathrm{Na}$ amostra 2 (Figura 4) verifica-se uma camada descarbonetada na superficial do fixador de aproximadamente $100 \mu \mathrm{m}$. Este defeito poderá gerar redução da resistência mecânica do elemento e redução do período de utilização do fixador.

\section{CONCLUSÕES}

Neste trabalho teve-se a oportunidade de se verificar a composição química e microestrutural dos fixadores de rodas empregados em automóveis provenientes de montadoras de origem francesa. Nas amostras observam-se variações entre os conjuntos de microestruturas e composições químicas que formam os materiais. Em decorrência disto, pode-se concluir que as amostras 2 e 3 possuem propriedades mecânicas melhores, quando comparada com a estrutura da amostra 1.

$\mathrm{Na}$ amostra 2 a camada descarbonetada pode gerar redução da vida útil deste elemento, uma vez que a maioria das falhas tem inicio na superfície do material. 
A verificação das durezas dos materiais indicam correlações diretas com as estruturas que formam estes materiais.

Não foram detectados marcas ou indícios evidentes de desgastes prematuros nas amostras analisadas.

\section{Agradecimentos}

Faculdade de Tecnologia de Sorocaba "José Crespo Gonzales"; Centro Paula Souza; Indústria Mecânica Braspar Ltda.; e CK Ltda.

\section{REFERÊNCIAS}

1 NIEMANN, G. Elementos de máquinas. São Paulo: Edgard Blucher. 2002.

2 ROHDE, R. A. Metalografia preparação de amostras: Uma abordagem prática. versão 3.0. LEMM Laboratório de Ensaios Mecânicos e Materiais, Outubro de 2010.

3 SAMUELS, L. E. Metallographic polishing by mechanical methods. Melbourne \& London Sir Isaac Pitman \& Sons Ltd. Austrália. 1971.

4 SOUZA, S. A. de. Composição química dos aços. São Paulo: Edgard Blucher, 1989.

5 COLPAERT, H. Metalografia dos produtos siderúrgicos comuns. 4. ed. São Paulo: Edgard Blucher, 2008.

6 PADILHA, Â. F.; AMBROZIO, F. F. Técnicas de análise microestrutural. São Paulo: Hemus, 2004. 